\title{
Shift work, nitrous oxide exposure, and spontaneous abortion among Swedish midwives
}

\author{
Gösta Axelsson, Gunnar Ahlborg Jr, Lennart Bodin
}

\begin{abstract}
Objectives-To study the relation between irregular work hours, nitrous oxide $\left(\mathrm{N}_{2} \mathrm{O}\right)$ exposure, and the risk of spontaneous abortion.

Methods-All 3985 female members of the Swedish Midwives Association in 1989, born in 1940 or later, received a questionnaire on exposure before and during all of their pregnancies. Questions on work conditions covered occupation, extent of employment, workplace, work schedules, use of anaesthetics, and work load. The association between exposure variables and spontaneous abortion was analysed by logistic regression models.

Results-Night work and three shift schedules among midwives showed increased odds ratios (ORs) (95\% confidence intervals $(95 \% \mathrm{CI})) \mathbf{1 . 6 3}(0.95-2 \cdot 81)$ and $1.49(0.86-2.59)$, respectively. The ORs of late spontaneous abortions (after the 12th week of pregnancy) was increased for night work 3.33 (1.13-9.87). Use of $\mathrm{N}_{2} \mathrm{O}$ (> $50 \%$ of the deliveries) was not associated with increased risk of spontaneous abortion OR 0.95 (0.62-1.47). Frequent or permanent shortage of staff was related to an increased risk of spontaneous abortions before the 13th week of pregnancy.

Conclusions-The results support the hypothesis that night work and high work load increase the risk of spontaneous abortion.
\end{abstract}

(Occup Environ Med 1996;53:374-378)

Keywords: shift work; nitrous oxide; work load; spontaneous abortion

Department of Environmental Medicine, Göteborg University, Gothenburg, Sweden G Axelsson

Department of Occupational and Environmental Medicine, Örebro Medical Centre Hospital, Örebro, Sweden

G Ahlborg

L Bodin

Correspondence to: Dr G Axelsson, Departmen of Environmental Medicine Medicinareg 16, S-413 90, Gothenburg, Sweden.

Accepted 31 January 1996
Exposure to anesthetic gases, including nitrous oxide $\left(\mathrm{N}_{2} \mathrm{O}\right)$, has been discussed as a suspected risk factor for spontaneous abortion since the 1970s. Although most studies deal with anaesthetic gases in general, an increased risk of spontaneous abortion was reported among dental assistants exposed to $\mathrm{N}_{2} \mathrm{O} \cdot{ }^{3}$ As many of the early studies have methodological shortcomings, the cause is often questioned. ${ }^{4}$ Although measures have been taken to reduce exposures, for example, in delivery rooms, it was still considered important to study whether exposure to this agent during recent years has resulted in an increased risk of spontaneous abortion.

Midwives working in delivery wards are exposed to varying extents to $\mathrm{N}_{2} \mathrm{O}$, which is used as an analgesic in the final stage of delivery. About one third of the midwives in Sweden work in delivery wards. This occupational group also often has inconvenient or irregular work hours. However, there are midwives not exposed to $\mathrm{N}_{2} \mathrm{O}$ and who work only during the day, and there thus exists suitable reference categories for an epidemiological study. It was therefore considered that midwives' work situations would be appropriate for studying the relation between irregular work hours, $\mathrm{N}_{2} \mathrm{O}$ exposure, and outcome of pregnancy.

This occupational group was also used to study the relation between these exposures and time to pregnancy. The results of that study will be reported in a separate paper.

\section{Subjects and methods}

STUDY POPULATION

The study population were all female members of the Swedish Midwives Association in 1989 who were born in 1940 or later. A questionnaire was sent to the 3985 women identified in the registry. After two reminders 3358 women (84.3\%) had answered the questionnaire. In total, 7599 pregnancies that began before 1989 were reported by 2786 women. Ongoing pregnancies at the time of the questionnaire were excluded.

To avoid memory bias and limit the analyses to work conditions that still prevail for midwives today, we decided before the analyses to exclude pregnancies that started before 1980. Altogether 3583 pregnancies during the period 1980-8 were reported in 1889 women. Before the analyses, all ectopic pregnancies (n $=79$ ) and all pregnancies among women who experienced five or more spontaneous abortions were excluded. Furthermore, the analyses were restricted to pregnancies during which the woman had worked more than half time during the first trimester and for which 
information on background variables was complete. The study then comprised 2667 pregnancies in 1587 women. The multivariate analyses of occupational exposures were based upon those 2505 pregnancies in which information about all requested occupational factors was available. The final analyses were made among the 1717 pregnancies during which the woman worked as a midwife.

\section{METHODS}

Data collection

The questionnaire contained items on all of the woman's pregnancies. As well as calendar year and age at the start of the pregnancy, work conditions during the month before pregnancy and during the first, second, and third trimesters were requested. Questions were also included about heavy lifting, chronic diseases, infection with high fever, smoking, consumption of alcohol, coffee, and analgesics.

The questions on working conditions covered occupation, extent of employment, workplace, and work schedules. Questions were also posed on exposure to $\mathrm{N}_{2} \mathrm{O}$, other anaesthetics, ultrasound equipment, and antineoplastic drugs. As well as a simple question on stress, there was also a question about shortage of staff.

Four different alternatives about work hours were presented: always day (reference category), always night, two shift schedule, and three shift schedule. Exposure to $\mathrm{N}_{2} \mathrm{O}$ was classified into three categories: no use of $\mathrm{N}_{2} \mathrm{O}$, use of $\mathrm{N}_{2} \mathrm{O}$ in up to $50 \%$ of assisted deliveries, use of $\mathrm{N}_{2} \mathrm{O}$ in more than $50 \%$ of assisted deliveries. There was also a question on the use of scavenging equipment in the delivery rooms. This question was dropped in the analysis, as many midwives reported that they were not sure if there was such equipment in the delivery rooms when they were pregnant.

For the questions on daily or almost daily contact with anaesthetic gases other than $\mathrm{N}_{2} \mathrm{O}$, ultrasound equipment, antineoplastic drugs, and stress, the answers were divided into two groups (yes or no), but staff resources were classified as never or almost never, sometimes, frequent, or permanent shortage of staff.

Potential confounding factors were also categorised: smoking $(0,1-9, \geqslant 10$ cigarettes a day), age $(\leqslant 29,30-34, \geqslant 35)$ previous spontaneous abortions $(0,1, \geqslant 2)$, coffee consumption $(0,1-3,4-6, \geqslant 7$ cups a day) and heavy lifting, which was defined as "approximately $10 \mathrm{~kg}$ or more" (<10,10-50, > 50 times a week). The question on infection with high fever had three alternatives (yes, no, don't know). In the final analysis, "no" and "don't know" were combined.

Spontaneous abortion was defined as intrauterine death of the embryo or fetus before the beginning of the 29th week of gestation. Spontaneous abortions that according to information in the questionnaire occurred before the 13th week of gestation were defined as "early abortions" and the rest as "late abortions."

A reported spontaneous abortion was accepted for analysis if the woman stated that it had been diagnosed by a physician or had been preceded by a positive pregnancy test. In $5 \%$ of all spontaneous abortions, the midwife reported that she was definitely sure that she had been pregnant, although the abortion had not been diagnosed by a physician or preceeded by a pregnancy test. These pregnancies were also accepted.

The reported occupational exposure during the first trimester was the basis for statistical analysis. For smoking and coffee drinking, the reported consumption during the month before pregnancy was used, as many women change smoking and coffee drinking habits during the first trimester. If such changes were made late in the first trimester, it was more likely that this was in a normal pregnancy than in a pregnancy where there was an early spontaneous abortion. Women with a normal pregnancy may have reported the consumption after the change in habit as representative for the first trimester, and the possible risk of spontaneous abortion due to these exposures may thus be overestimated if reported exposures during the first trimester were used in the analysis. We excluded alcohol use in the analyses as only $6 \%$ reported use every week during the month before pregnancy and $1 \%$ during the first trimester.

In this cohort, about a third of the pregnancies occurred when the woman had an occupation other than midwife-for example, nurse. These pregnancies were also included in the analysis of background variables and occupational factors other than work hours and $\mathrm{N}_{2} \mathrm{O}$ exposure. The remaining analyses were restricted to pregnancies in which the woman worked as a midwife.

\section{STATISTICS}

The binary outcome "spontaneous abortion" was analysed by bivariate logistic regression models. In those analyses in which the spontaneous abortion was classified into three classes according to the time of the event, a polytomous logistic regression model was used. In this model, the three categories of the outcome variable (no spontaneous abortion, abortion before the 13th week, abortion after the 12th week) were considered a trichotomous nominal variable. The primary analyses were done with the pregnancies as the unit of analysis. It was assumed that there was independence of pregnancies within an individual woman. Secondary analyses were performed where this assumption was relaxed and a model with a random effect for each woman was included, thus allowing for correlated binary data. The model is referred to as a logistic binomial regression model. The statistical programs EPILOG, ${ }^{6}$ EGRET, ${ }^{7}$ and $\mathrm{BMDP}^{8}$ were used.

In the first step of the analysis only one of the explanatory variables was included in each of the analyses. The results of this first step are reported as crude odds ratios (ORs). The second step of the analysis included a subset of the explanatory variables, selected on a hypothesis specified originally. The ORs from this analysis are the adjusted ORs (95\% confidence intervals (95\% CI)). 
Table 1 Numbers of posed and answered questionnaires and number of pregnant women among those who answered the questionnaire

\begin{tabular}{lr}
\hline Mailed questionnaires & 3985 \\
Answered questionnaires: & 3358 \\
Previously pregnant & 2786 \\
Never pregnant & 501 \\
Pregnant for the first time & 71 \\
\hline
\end{tabular}

Table 2 OR of spontaneous abortion in relation to potential confounding variables (all variables in the table are included in the logistic regression model in calculating adjusted ORs)

\begin{tabular}{|c|c|c|c|c|c|}
\hline & Pregnancies & $\begin{array}{l}\text { Spontaneous } \\
\text { abortions }\end{array}$ & $\begin{array}{l}\text { Crude } \\
\text { OR }\end{array}$ & $\begin{array}{l}\text { Adjusted } \\
\text { OR }\end{array}$ & $(95 \% C I)$ \\
\hline \multicolumn{6}{|l|}{ Age: } \\
\hline$\leqslant 29$ & 1269 & 149 & $1 \cdot 0$ & $1 \cdot 0$ & - \\
\hline $30-34$ & 1012 & 152 & 1.33 & $1 \cdot 24$ & $(0.94-1.63)$ \\
\hline$\geqslant 35$ & 386 & 75 & 1.81 & 1.68 & $(1 \cdot 17-2 \cdot 43)$ \\
\hline \multicolumn{6}{|l|}{ Pregnancy number: } \\
\hline 1 & 765 & 105 & $1 \cdot 0$ & $1 \cdot 0$ & - \\
\hline 2 & 837 & 113 & 0.98 & 0.94 & $(0 \cdot 69-1 \cdot 27)$ \\
\hline 3 & 618 & 87 & 1.03 & 0.85 & $(0 \cdot 59-1 \cdot 21)$ \\
\hline 4 & 286 & 39 & 0.99 & 0.69 & $(0 \cdot 43-1 \cdot 10)$ \\
\hline $5+$ & 161 & 32 & $1 \cdot 56$ & 0.84 & $(0 \cdot 48-1 \cdot 48)$ \\
\hline \multicolumn{6}{|c|}{ Previous spontaneous abortion: } \\
\hline 0 & 2118 & 288 & $1 \cdot 0$ & $1 \cdot 0$ & - \\
\hline 1 & 456 & 64 & 1.04 & 1.04 & $(0 \cdot 75-1 \cdot 45)$ \\
\hline$\geqslant 2$ & 93 & 24 & $2 \cdot 21$ & $2 \cdot 20$ & $(1 \cdot 25-3 \cdot 87)$ \\
\hline \multicolumn{6}{|l|}{ Calendar year: } \\
\hline 1980 & 332 & 38 & 1.0 & 1.0 & - \\
\hline 1981 & 290 & 29 & 0.86 & 0.91 & $(0.54-1.53)$ \\
\hline 1982 & 320 & 46 & $1 \cdot 30$ & $1 \cdot 27$ & $(0 \cdot 80-2.03)$ \\
\hline 1983 & 303 & 39 & $1 \cdot 14$ & 1.20 & $(0.74-1.94)$ \\
\hline 1984 & 317 & 38 & 1.05 & $1 \cdot 11$ & $(0 \cdot 68-1.81)$ \\
\hline 1985 & 322 & 52 & 1.49 & $1 \cdot 47$ & $(0 \cdot 92-2 \cdot 34)$ \\
\hline 1986 & 254 & 43 & $1 \cdot 58$ & 1.54 & $(0.95-2.51)$ \\
\hline 1987 & 267 & 53 & 1.92 & 1.79 & $(1 \cdot 11-2 \cdot 88)$ \\
\hline 1988 & 262 & 38 & 1.31 & $1 \cdot 24$ & $(0.74-2.06)$ \\
\hline \multicolumn{6}{|c|}{ Heavy lifting (times/week): } \\
\hline Seldom or never & 833 & 128 & $1 \cdot 0$ & $1 \cdot 0$ & - \\
\hline$<10$ & 910 & 129 & 0.91 & 0.93 & $(0 \cdot 71-1 \cdot 22)$ \\
\hline $10-50$ & 712 & 94 & 0.84 & 0.84 & $(0 \cdot 62-1 \cdot 13)$ \\
\hline$>50$ & 212 & 25 & $0 \cdot 74$ & 0.74 & $(0 \cdot 46-1 \cdot 19)$ \\
\hline \multicolumn{6}{|l|}{ Coffee (cups/day): } \\
\hline 0 & 325 & 38 & $1 \cdot 0$ & 1.0 & - \\
\hline $1-3$ & 1079 & 145 & $1 \cdot 17$ & $1 \cdot 14$ & $(0 \cdot 78-1 \cdot 69)$ \\
\hline $4-6$ & 1070 & 158 & $1 \cdot 31$ & $1 \cdot 19$ & $(0 \cdot 80-1 \cdot 75)$ \\
\hline$\geqslant 7$ & 193 & 35 & 1.67 & 1.40 & $(0 \cdot 83-2 \cdot 36)$ \\
\hline \multicolumn{6}{|c|}{ Smoking (cigarettes/day): } \\
\hline 0 & 2085 & 277 & $1 \cdot 0$ & $1 \cdot 0$ & - \\
\hline $1-9$ & 177 & 19 & $0 \cdot 78$ & 0.74 & $(0 \cdot 45-1 \cdot 22)$ \\
\hline$\geqslant 10$ & 405 & 80 & $1 \cdot 61$ & 1.50 & $(1 \cdot 12-2 \cdot 02)$ \\
\hline \multicolumn{6}{|c|}{ Infection with high fever: } \\
\hline No & 2172 & 286 & $1 \cdot 0$ & $1 \cdot 0$ & - \\
\hline Don't remember & 220 & 36 & $1 \cdot 29$ & $1 \cdot 32$ & $(0.89-1.97)$ \\
\hline Yes & 275 & 54 & 1.61 & $1 \cdot 71$ & $(1 \cdot 22-2 \cdot 39)$ \\
\hline \multicolumn{6}{|l|}{ Analgesic drugs: } \\
\hline No & 2495 & 346 & $1 \cdot 0$ & 1.0 & - \\
\hline Don't remember & 104 & 16 & $1 \cdot 13$ & 0.94 & $(0.53-1 \cdot 67)$ \\
\hline Yes & 68 & 14 & $1 \cdot 61$ & $1 \cdot 40$ & $(0 \cdot 75-2 \cdot 60)$ \\
\hline
\end{tabular}

Table 3 OR of spontantous abortion in relation to occupational exposures (ORs are adjusted for calendar year, age, previous spontaneous abortion, smoking, and infection as well as for the variables in the table)

\begin{tabular}{|c|c|c|c|c|c|}
\hline Exposure & Pregnancies & $\begin{array}{l}\text { Spontaneous } \\
\text { abortions }\end{array}$ & $\begin{array}{l}\text { Crude } \\
\text { OR }\end{array}$ & $\begin{array}{l}\text { Adjusted } \\
\text { OR }\end{array}$ & $(95 \% C I)$ \\
\hline \multicolumn{6}{|l|}{ Full time work: } \\
\hline $\begin{array}{l}\text { No } \\
\text { Yes }\end{array}$ & $\begin{array}{l}1173 \\
1332\end{array}$ & $\begin{array}{l}158 \\
192\end{array}$ & $\begin{array}{l}1 \cdot 0 \\
1 \cdot 08\end{array}$ & $\begin{array}{l}1 \cdot 0 \\
1 \cdot 14\end{array}$ & $\overline{(0.88-1 \cdot 47)}$ \\
\hline \multicolumn{6}{|l|}{ Work time: } \\
\hline Always day & 567 & 71 & $1 \cdot 0$ & $1 \cdot 0$ & - \\
\hline Always night & 367 & 57 & $1 \cdot 28$ & $1 \cdot 30$ & $(0 \cdot 83-2 \cdot 01)$ \\
\hline Two shift & 1128 & 157 & $1 \cdot 13$ & $1 \cdot 19$ & $(0.85-1 \cdot 68)$ \\
\hline Three shift & 443 & 65 & $1 \cdot 20$ & $1 \cdot 23$ & $(0 \cdot 78-1.94)$ \\
\hline \multicolumn{6}{|l|}{ Use of $\mathrm{N}_{2} \mathrm{O}$ : } \\
\hline No & 1262 & 168 & $1 \cdot 0$ & $1 \cdot 0$ & - \\
\hline$\leqslant 50 \%$ of deliveries & 538 & 71 & 0.99 & 0.95 & $(0 \cdot 66-1 \cdot 35)$ \\
\hline $\begin{array}{l}>50 \% \text { of deliveries } \\
\text { An }\end{array}$ & 705 & 111 & $1 \cdot 22$ & $1 \cdot 17$ & $(0.84-1.62)$ \\
\hline \multicolumn{2}{|l|}{ Anaesthetic gas, other than $\mathrm{N}_{2} \mathrm{O}$ : } & 335 & $1 \cdot 0$ & $1 \cdot 0$ & - \\
\hline Yes & 87 & 15 & $1 \cdot 30$ & 1.08 & $(0.59-1.96)$ \\
\hline \multicolumn{6}{|l|}{ Ultrasound: } \\
\hline No & 2190 & 300 & $1 \cdot 0$ & $1 \cdot 0$ & - \\
\hline Yes & 315 & 50 & $1 \cdot 19$ & 1.01 & $(0 \cdot 71-1 \cdot 42)$ \\
\hline \multicolumn{6}{|l|}{ Antineoplastic drugs: } \\
\hline No & 2420 & 333 & $1 \cdot 0$ & $1 \cdot 0$ & - \\
\hline Yes & 85 & 17 & 1.57 & $1 \cdot 46$ & $(0 \cdot 82-2 \cdot 59)$ \\
\hline \multicolumn{6}{|l|}{ Stress: } \\
\hline No & 1317 & 166 & $1 \cdot 0$ & $1 \cdot 0$ & - \\
\hline Yes & 1188 & 184 & $1 \cdot 27$ & $1 \cdot 10$ & $(0 \cdot 86-1 \cdot 42)$ \\
\hline \multicolumn{6}{|l|}{ Shortage of staff: } \\
\hline Never & 1391 & 185 & $1 \cdot 0$ & $1 \cdot 0$ & - \\
\hline Sometimes & 826 & 108 & 0.98 & 0.92 & $(0 \cdot 71-1 \cdot 20)$ \\
\hline Frequent or permanent & 288 & 57 & 1.61 & 1.45 & $(1.01-2.06)$ \\
\hline
\end{tabular}

The explanatory variables were categorised. Quantitative variables such as age and number of cigarettes smoked were categorised to allow for non-linear effects on the outcome variables. The reference category chosen is indicated in the tables. In some final analyses, categories that gave similar estimates of the ORs were aggregated. This was done for age ( $\leqslant 29$ and 30-34 were joined) and calendar year (1986 and 1987 formed one category and the remaining years the other).

Interaction effects were analysed and particular attention was paid to the interaction effects for full time and part time work schedules. In the final analyses, none of the interaction effects were included in the models as their contribution to the goodness of fit was negligable.

\section{Results}

Table 1 shows that 501 out of the 3358 women who answered the questionnaire reported that they had never been pregnant. Of these, $130(26 \%)$ had tried to become pregnant without success. Of the 97 neverpregnant women who had sought medical assistance for difficulties in becoming pregnant, $57(59 \%)$ had received a medical explanation for their infertility.

Of the 2667 pregnancies among the 1587 women who had worked more than half time during the first trimester, $14.1 \%$ ended in spontaneous abortion and $3.3 \%$ in induced abortion.

Table 2 shows the number of pregnancies and spontaneous abortions and the ORs in relation to background variables. Significantly increased ORs were found among women who were at least 35 years old or had had at least two previous spontaneous abortions. Smoking at least 10 cigarettes a day and infection with a high fever were also independent risk factors. In comparison with 1980 , the OR for spontaneous abortion in 1987 was significantly increased.

Table 3 reports the adjusted ORs for occupational exposures among all pregnancies in which the woman worked more than half time. The only significantly increased risk (OR 1.45 , 95\% CI 1.01-2.06) was found in pregnancies in which it was reported that there was often a shortage of staff. The ORs for night work and shift schedules varied between $1 \cdot 19$ and 1.30 compared with day work only. The highest $\mathrm{N}_{2} \mathrm{O}$ category had an OR of $1 \cdot 17(0 \cdot 84-1 \cdot 62)$.

Table 4 shows the adjusted ORs for spontaneous abortions only in those pregnancies in which the woman worked as a midwife during the first trimester. Night work and three shift schedules showed insignificantly increased ORs, $1.63(0.95-2.80)$ and $1.49(0.86-2.59)$ respectively. Complementary analyses showed only small differences between full time work and part time work. The increased OR for pregnancies in which a frequent shortage of staff had been reported was most evident in part time work. Again, use of $\mathrm{N}_{2} \mathrm{O}$ showed no association with increased risk of spontaneous abortion. 
Table 4 OR for spontaneous abortion in pregnancies in which the woman worked as a midwife (ORs are adjusted for calendar year, age, previous spontaneous abortion, smoking, and infection as well as for the variables in the table)

\begin{tabular}{|c|c|c|c|c|c|}
\hline Exposure & Pregnancies & $\begin{array}{l}\text { Spontaneous } \\
\text { abortions }\end{array}$ & $\begin{array}{l}\text { Crude } \\
\text { OR }\end{array}$ & $\begin{array}{l}\text { Adjusted } \\
\text { OR }\end{array}$ & $(95 \% C I)$ \\
\hline \multicolumn{6}{|l|}{ Full time work: } \\
\hline No & 913 & 131 & $1 \cdot 0$ & $1 \cdot 0$ & - \\
\hline Yes & 804 & 121 & 1.06 & $1 \cdot 18$ & $(0 \cdot 88-1 \cdot 59)$ \\
\hline \multicolumn{6}{|l|}{ Working time: } \\
\hline Always day & 422 & 60 & $1 \cdot 0$ & $1 \cdot 0$ & - \\
\hline Always night & 286 & 51 & $1 \cdot 31$ & $1 \cdot 63$ & $(0.95-2 \cdot 80)$ \\
\hline Two shift & 638 & 83 & 0.90 & $1 \cdot 16$ & $(0 \cdot 73-1 \cdot 84)$ \\
\hline Three shift & 371 & 58 & $1 \cdot 12$ & 1.49 & $(0 \cdot 86-2 \cdot 59)$ \\
\hline \multicolumn{6}{|l|}{ Use of $\mathrm{N}_{2} \mathrm{O}$ : } \\
\hline No & 598 & 89 & 1.0 & $1 \cdot 0$ & - \\
\hline$\leqslant 50 \%$ of deliveries & 495 & 65 & $0 \cdot 86$ & $0 \cdot 75$ & $(0 \cdot 48-1 \cdot 19)$ \\
\hline$>50 \%$ of deliveries & 624 & 98 & $1 \cdot 07$ & 0.95 & $(0 \cdot 62-1 \cdot 47)$ \\
\hline \multicolumn{6}{|l|}{ Shortage of staff: } \\
\hline Never & 951 & 130 & $1 \cdot 0$ & $1 \cdot 0$ & - \\
\hline Sometimes & 576 & 82 & 1.05 & 1.06 & $(0 \cdot 79-1 \cdot 44)$ \\
\hline Frequent or permanent & 190 & 40 & $1 \cdot 68$ & $1 \cdot 64$ & $(1 \cdot 09-2 \cdot 48)$ \\
\hline
\end{tabular}

To evaluate the consistency of the results for work hours an analysis was also made for the data in table 4 with a restriction to first pregnancies $(n=428)$. A significantly increased OR was found for night work, $6 \cdot 89$ $(1 \cdot 43-33 \cdot 3)$ and two shift schedules, $2 \cdot 70$ $(1 \cdot 09-6 \cdot 72)$. The same tendency was found for three shift schedules but was not significant, OR $2.57(0 \cdot 80-8 \cdot 31)$.

Table 5 shows the ORs separately for early and late spontaneous abortions in the pregnancies of midwives. A significantly increased OR for early spontaneous abortions was found in pregnancies associated with a frequent shortage of staff, $1.94(1.25-3.01)$, but work at night was associated with an increased risk of late abortions, OR 3.33 (1·13-9.87).

All ORs reported in the tables were calculated by logistic regression models with an assumption of independence of pregnancies within the individual woman. The secondary analyses allowing for dependencies between pregnancies of the same woman, gave ORs which differed little from those reported in the tables.

\section{Discussion}

Information on spontaneous abortion was obtained only from the questionnare. Criteria for inclusion in the analysis were the abortion having been reported as diagnosed by a physi- cian or the pregnancy having been preceded by a pregnancy test. In a previous study in a general population, the agreement between these factors and information in hospital records was very high, ${ }^{9}$ and no confirmation of diagnosis was thus made in this cohort. As it is likely that this occupational group has a better knowledge of pregnancy diagnostics than the general population, those spontaneous abortions were also accepted (5\% of all spontaneous abortions) in which no test was made, but for which the woman reported that she was certain that she had been pregnant.

Pregnancies that began before 1980 were excluded in the analysis, mainly for two reasons. Firstly, $\mathrm{N}_{2} \mathrm{O}$ exposure during the 1970 s was probably quite different from the exposure situation at the time of the study. Secondly, by excluding pregnancies far back in time, the risk of memory bias was reduced.

For background variables, increased risks of miscarriage were found in women of 35 years or older, in women who had had more than one previous spontaneous abortion, in smokers (at least 10 cigarettes a day), and in women who reported infection with a high fever during the first trimester. These factors are all known risk factors of spontaneous abortion. No significantly increased risks were associated with heavy lifting during the first trimester, which is in agreement with a previous study in Sweden. ${ }^{10}$

The classification of $\mathrm{N}_{2} \mathrm{O}$ exposure was based upon the proportion of deliveries with $\mathrm{N}_{2} \mathrm{O}$ anaesthetic in which the midwife assisted, as there was an indication that the question on the number of deliveries exposed to $\mathrm{N}_{2} \mathrm{O}$ a week could have been misinterpreted.

It has previously been shown that work practice, type of mask, scavenging equipment, and room ventilation influence the $\mathrm{N}_{2} \mathrm{O}$ exposure of midwives. ${ }^{11}$ The two exposure categories used could thus overlap for exposure level and exposure time. However, there were no indications that either of the two classes were associated with an increased risk of spontaneous abortion. The point estimates of the ORs were close to one in pregnancies of midwives, both for early and late abortions.

There are many published studies reporting investigations of exposure to anaesthetic gases in general and spontaneous abortion, ${ }^{12}$ but only

Table 5 ORs for early and late spontaneous abortion in pregnancies in which the woman worked as a midwife (ORs are adjusted for calendar year, age, previous spontaneous abortions, and infection as well as for the variables included in the table)

\begin{tabular}{|c|c|c|c|c|c|c|c|c|c|}
\hline Exposure & Pregnancies & $\begin{array}{l}\text { Early } \\
\text { spontaneous } \\
\text { abortions }\end{array}$ & $\begin{array}{l}\text { Crude } \\
\text { OR }\end{array}$ & $\begin{array}{l}\text { Adjusted } \\
\text { OR }\end{array}$ & $(95 \% C I)$ & $\begin{array}{l}\text { Late } \\
\text { spontaneous } \\
\text { abortion }\end{array}$ & $\begin{array}{l}\text { Crude } \\
\text { OR }\end{array}$ & $\begin{array}{l}\text { Adjusted } \\
\text { OR }\end{array}$ & $(95 \% C I)$ \\
\hline \multicolumn{10}{|l|}{ Full time work: } \\
\hline No & 911 & 105 & $1 \cdot 0$ & $1 \cdot 0$ & - & 26 & $1 \cdot 0$ & $1 \cdot 0$ & - \\
\hline Yes & 800 & 95 & 1.04 & 1.06 & $(0 \cdot 76-1 \cdot 47)$ & 26 & $1 \cdot 15$ & 1.92 & $(1 \cdot 00-3 \cdot 71)$ \\
\hline \multicolumn{10}{|l|}{ Working time: } \\
\hline Always day & 421 & 50 & $1 \cdot 0$ & $1 \cdot 0$ & - & 10 & $1 \cdot 0$ & $1 \cdot 0$ & - \\
\hline Always night & 285 & 34 & 1.05 & $1 \cdot 28$ & $(0 \cdot 69-2 \cdot 36)$ & 17 & $2 \cdot 62$ & $3 \cdot 33$ & $(1 \cdot 13-9 \cdot 87)$ \\
\hline Two shift & 635 & 65 & 0.85 & $1 \cdot 17$ & $(0.70-1.94)$ & 18 & $1 \cdot 18$ & $1 \cdot 11$ & $(0.42-2 \cdot 94)$ \\
\hline Three shift & 370 & 51 & $1 \cdot 18$ & $1 \cdot 74$ & $(0 \cdot 95-3 \cdot 20)$ & 7 & $0 \cdot 81$ & $0 \cdot 71$ & $(0 \cdot 20-2 \cdot 48)$ \\
\hline \multicolumn{10}{|l|}{ Use of $\mathrm{N}_{2} \mathrm{O}$ : } \\
\hline No $\leqslant 50 \%$ of deliveries & 596 & 73 & $1 \cdot 0$ & $1 \cdot 0$ & - & 16 & $1 \cdot 0$ & $1 \cdot 0$ & - \\
\hline$\leqslant 50 \%$ of deliveries & 492 & 50 & $0 \cdot 81$ & $0 \cdot 70$ & $(0 \cdot 42-1 \cdot 17)$ & 15 & $1 \cdot 11$ & $1 \cdot 02$ & $(0.41-2 \cdot 53)$ \\
\hline $\begin{array}{l}>50 \% \text { of deliveries } \\
\text { Shortage of staff: }\end{array}$ & 623 & 77 & 1.02 & 0.94 & $(0.58-1.53)$ & 21 & $1 \cdot 27$ & 1.05 & $(0.44-2 \cdot 52)$ \\
\hline \multicolumn{10}{|l|}{ Shortage of staff: } \\
\hline $\begin{array}{l}\text { Never } \\
\text { Sometimes }\end{array}$ & $\begin{array}{l}950 \\
572-r\end{array}$ & 98 & $1 \cdot 0$ & $1 \cdot 0$ & & 32 & $1 \cdot 0$ & $1 \cdot 0$ & \\
\hline $\begin{array}{l}\text { Sometimes } \\
\text { Frequent or permanent }\end{array}$ & $\begin{array}{l}372 \\
189\end{array}$ & $\begin{array}{l}67 \\
35\end{array}$ & $\begin{array}{l}1.14 \\
1.97\end{array}$ & $\begin{array}{l}1.15 \\
1.94\end{array}$ & $(0.82-1.61)$ & $\begin{array}{r}15 \\
5\end{array}$ & 0.78 & $0 \cdot 79$ & $(0 \cdot 42-1 \cdot 49)$ \\
\hline Frequent or permanent & 109 & 33 & 1.97 & 1.94 & $(1.23-3.01)$ & 5 & 0.86 & $0 \cdot 80$ & $(0 \cdot 30-2 \cdot 13)$ \\
\hline
\end{tabular}


a few in which exposure to $\mathrm{N}_{2} \mathrm{O}$ has been studied specifically. ${ }^{313}$ In the earliest of these ${ }^{3}$, heavy use of anaesthetics ( $>8$ hours a week) was associated with a significantly increased relative risk (RR) of spontaneous abortion (RR 2.4) compared with non-use. In the most recent study, ${ }^{13}$ a relative risk of 2.6 was found for three or more hours a week in offices without scavenging equipment. For scavenged $\mathrm{N}_{2} \mathrm{O}$ exposure, the adjusted $R R$ was 1.0 compared with no exposure.

It has been reported that exposure levels in dental offices in the United States may exceed $1000 \mathrm{ppm}$ when no scavenging equipment is used. ${ }^{14}$ We asked Swedish hospitals for hygienic measurement protocols concerning $\mathrm{N}_{2} \mathrm{O}$ exposure in delivery rooms during the 1980 s. Peak exposures frequently exceeded $500 \mathrm{ppm}$ where special scavenging or forced ventilation was not used. Correct use of such equipment reduced exposures to well below $100 \mathrm{ppm}$. Eight hour time weighted average exposure is in most cases very low for midwives owing to the infrequent and short use of $\mathrm{N}_{2} \mathrm{O}$ analgesia. The reason why no increased risk of spontaneous abortion is found in the Swedish study may thus be that exposures are lower than in dental offices in the United States or that the exposure classification in our study was too crude.

Previous studies of the risk of spontaneous abortion and working time have shown diverging results. In a Swedish study among hospital personnel, ${ }^{2}$ an OR of 1.42 was found if irregular working time was reported, which is quite similar to the present study. That study did not indicate any increased risk of night work. In Finland, three shift schedules among hospital personnel were found to be associated with a $50 \%$ increased risk of spontaneous abortion. ${ }^{15}$ In a prospective study in Montreal McDonald et $a l^{16}$ found a significantly increased risk of spontaneous abortion for shift work, but only among hospital workers. In a case-control study in Santa Clara, United States on physical exertion there was a risk of spontaneous abortion, ORs < 1 were found for evening work, night work, and shift work, ${ }^{17}$ whereas a Canadian study reported increased ORs for evening work only. ${ }^{18}$ These studies were considerably smaller than the present study among midwives.

In our study, the question on work hours was answered in $99 \%$ of the questionnaires. We thus think that the women are certain of which of the four alternatives was the most relevant, and that the risk of misclassification was low. However, the question on the number of nights a month was often incompletely answered and was thus excluded in the analysis. An increased (but insignificant) OR of spontaneous abortion was found among midwives working nights or three shift schedules. The increase in risk related to night work was found mainly for spontaneous abortions after the 12th week of pregnancy, but three shift schedules were associated with an increased risk before the 13th week.

To avoid potential bias arising from the outcome of one pregnancy influencing the woman's choice of work hours during the next pregnancy, a separate analysis was made among first pregnancies. In spite of the number of pregnancies analysed being reduced to less than one third of the total number, a significantly increased risk of night work and two shift schedules was found. We thus conclude that night work and a frequent or permanent shortage of staff was associated with significantly increased risks in most analyses. The question on shortage of staff was added to the questionnaire to study the influence of stress in terms of work load. A more detailed study was made among the pregnancies in which a frequent or permanent shortage of staff was reported to identify whether there was a cluster of women who experienced more than one spontaneous abortion, indicating recall bias. Five women experienced more than one spontaneous abortion during the study period, 29 experienced one and 123 experienced no spontaneous abortion. This distribution was not different from the cohort in general. Further analyses indicated that the high rate of spontaneous abortion in this subgroup was attributed mainly to midwives who worked in other places than delivery rooms. We conclude that a high work load also increases the risk of spontaneous abortion.

This study was supported by the Swedish Work Environmen Fund (grant 89-0459). The authors wish to thank Inglis Bryngelsson and Barbro Aldäng for assistance in collection and handling of the data; and the Swedish Midwives Assocoation and the Association of County Councils for supporting the study.

1 Scott AJ, LaDou J. Shiftwork: effects on sleep and health with recommendations for surveillance and screening. Occup Med 1990;5:273-99.

2 Axelsson G, Rylander R, Molin I. Outcome of pregnancy in relation to irregular and inconvenient work schedules. $\mathrm{Br}$ f Ind Med 1989;46:393-8.

3 Cohen EN, Brown BW, Wu ML, Whitcher CE, Brodsky $\mathrm{JB}$, Gift HC, et al. Occupational disease in dentistry and chronic exposure to trace anesthetic gases. Am $尹$ Dent Assoc 1980;101:21-31.

4 Axelsson G, Rylander R. Exposure to anaesthetic gases and spontaneous abortion: response bias in a postal question naire study. Int $\mathcal{F}$ Epidemiol 1982;11:250-6.

5 Kline J. Maternal occupation: effects on spontaneous abortions and malformations. Occup Med 1986;1:381-403.

6 EPILOG. Epilog Plus, version 3. Pasadena, CA: Epicente Software, 1993.

7 EGRET. Egret, revision 4. Seattle, WA: Statistics and Epidemiology Research Corporation, 1993.

8 BMDP. BMDP Release 7. Los Angeles, CA: BMDP Statistical Software, 1992.

9 Axelsson G. Use of questionnaires in a study of spontaneous abortion in a general population. 7 . Epidemiol Community Health 1990;44:202-4.

10 Ahlborg Jr G, Bodin L, Hogstedt C. Heavy lifting during pregnancy-a hazard to the fetus? A prospective study. Int $\mathcal{F}$ Epidemiol 1990;19:90-7.

11 Bernow J, Björdahl J, Wiklund KE. Pollution of deliver ward air by nitrous oxide. Effects of various modes of room ventilation, excess and close scavenging. Acta Anaesthesiol Scand 1984;28:119-23.

12 Friedman JM. Teratogen update: anesthetic agents. Teratology 1988;37:69-77.

13 Rowland AS, Baird DD, Shore DL, Weinberg CR, Savitz DA, Wilcox AJ. Nitrous oxide and spontaneous abortion in female dental assistants. Am $\mathcal{f}$ Epidemiol 1994; in female

14 McGlothin JD, Jensen PA, Todd WF, Fischbach TJ. Study protocol: control of anestetic gases in dental operatories. Cincinnati: National Institute of Occupational Safety and Health, 1988

15 Hemminki K, Kyyronen P, Lindbohm M-L. Spontaneous abortions and malformations in the offspring of nurses exposed to anaesthetic gases, cytostatic drugs, and othe potential hazards in hospitals, based on registered information of outcome. $\mathcal{F}$ Epidemiol Community Health 1985 39:141-7.

16 McDonald AD, McDonald JC, Armstrong B, Cherry NM Côté $\mathrm{R}$, Lavoie J, et al. Fetal death and work in pregnancy. $\mathrm{Br}$ F Ind Med 1988;45:148-57.

17 Eskenazi B, Fenster L, Wight S, English P, Windham G, Swan S. Physical exertion as a risk factor for spontaneous abortion. Epidemiology 1994;5:6-13.

18 Infante-Rivard C, David M, Gauthier R, Rivard G-E Pregnancy loss and work schedule during pregnancy. Epidemiology 1993;4:73-5. 